\title{
THE COMPLEXITY OF LEARNING AND UNDERSTANDING IN CHEMICAL EDUCATION: ANALYSIS AND INTERVENTION USING DETAILED LEARNING PATHWAYS
}

\section{Thomas Toczkowski}

Didactics of Chemistry I, Department of Chemistry and Chemical Biology, TU Dortmund University, thomas.toczkowski@tu-dortmund.de

\section{Bernd Ralle}

Didactics of Chemistry I, Department of Chemistry and Chemical Biology, TU Dortmund University, bernd.ralle@tu-dortmund.de

\begin{abstract}
Using detailed learning pathways to map out students' construction of knowledge in the topic of stoichiometric relations and chemical formulae; we try to find a new structure to teach enduring 'stumbling stones' on every single student's way to a proper chemical understanding. This paper gives insights into the method of process-focused analysis and the associated design experiment. Furthermore, it presents an individual students' strategy to calculate stoichiometric relations that could be used as initial help for slower learners.
\end{abstract}

Keywords Stochiometric relations, chemical formulae, stumbling stones, misconceptions, understanding, learning pathways, didactical design research

\section{Background}

Dealing with stoichiometric relations and chemical formulae appears to be an enduring 'stumbling stone' (Schmidt, 1990) on the students' way towards a proper understanding of chemistry. As Taskin and Bernholt (2014) show in their review, it has been a recurrent topic of research in chemical education for the last decades. Despite good ideas to reduce the complexities and difficulties, as for example Rossa (1998), Wohlmuth (2005) or Fach (2007) suggest, there is still evidence of uncertainties and misconceptions while dealing with chemical formulae in students' approaches as the following examples report.

Bernholt et al. (2012) reveal students' problems to connect chemical formulae with illustrations of particles: up to $66 \%$ of the participants were not able to point out, which kind of particle (molecule, ion, or atom) is meant by the formula of a compound. A similar observation is noted by Claesgens and Stacy (2003): students were asked to investigate compounds. They did not consider atoms or molecules but related characteristics like the amount of a substance to macroscopic properties instead. Earlier, Stübs and Wegner (1990) were able to show how many students use the formulae of compounds as simple abbreviations for the compound's name.

The aforementioned and further reported difficulties and misunderstandings were summarized by Bernholt et al. (2012) as having three main causes:

- A lack of understanding of the language of chemical symbols. 
- Different kinds of formulae are either under- or over-interpreted.

- Ideas and models of particles are not adequately connected with symbolic representations and vice versa.

Many difficulties can be explained by these three causes, though there are other views on that topic. As an example, Aufschnaiter and Rogge (2010) mention the difference between misconceptions and missing conceptions. They state that students often do not argument with individual existing misconceptions. Instead, they construct explorative conceptions 'just in time' when they need them. Aufschnaiter and Rogge recommend that it is necessary to offer enough time and opportunities to the students to practice and bring in their ideas, so as to elaborate the conceptions into stable and rule-based strategies.

In order to change the habits of learning and teaching towards a better understanding, it is important to recognise and analyse students' thinking to know exactly where the obstacles can be found.

Hence, the question has to be answered as to where and how can the learning processes be analysed and how can results of such an analysis be used to improve students' understanding?

Johnstone (1997) states that many of the students' problems originate in the insufficient capacity of handling information due to a very high level of complexity of the task:

List for yourself the number of things the student has to do [while solving an experimental task], the number of observations that have to be made (...) and the number of theoretical ideas that have to be recalled to make sense of these observations and instructions. The total is staggering! (Johnstone, 1997, p. 266)

A similar approach is described by Scott (1992). He states the different pathways students move on, coming from their previous knowledge to a sufficient understanding of - in his case - the structure of matter. This 'conceptual pathway' is unique to every single student, depending on their prior conceptions and the ideas they bring in. Thus, two pathways of students with similar preconditions and leading to a similar 'goal' can be comparable. Scott uses these pathways to map out the structure of a single student in a whole series of lessons in physics and analyses the upcoming ideas and obstacles. He concludes that

if we want to learn more about the development of children's conceptions during instructions then we need to carry out further research into conceptual pathways. (Scott, 1992, p. 223)

Drawing on this idea, Petri and Niedderer (1998) improve the conceptual pathways into learning pathways including intermediate conceptions, trying to better understand how students think. Within this procedure several steps of students' ideas are identified, which document the individual learning process, while they have not yet reached the teacher's aim. The authors point out that students use learning pathways by providing their own processes of cognitive construction. This often differs from what the teachers have intended. For further research Petri and Niedderer suggest a more in-depth analysis of the isolated construction processes which occur during learning. This is our starting point for the analysis of detailed learning pathways. 


\section{Aims}

In summary two main research questions are to be investigated:

i. How can students' ways of understanding chemical formulae and stoichiometric relations be analysed in a more detailed way and how can the results affect the structuring of these topics?

ii. How can students' individual strategies of solving a task be identified and investigated? Can they even be used to support other learners?

\section{Research methodology}

This research project is embedded in the interdisciplinary FUNKEN research project at TU Dortmund University, following the paradigm of didactical design research in the Dortmund model (Prediger et al., 2012; english phrasing: Prediger \& Zwetzschler, 2013). There are two different but interconnected aims of this approach: on the one hand it intends to further the better understanding of individual learning processes and obstacles. On the other hand, new or alternative teaching-learning arrangements shall be developed. Both aims correspond with the recommendations and results of Gravemeijer and Cobb (2006).

\subsection{Specifying and structuring learning goals and contents}

In a cyclic line of steps, the intended learning goals and contents have to be primarily specified and structured. Regarding our research questions it was necessary to become familiar with 'stumbling stones' and strategies of handling stoichiometric relations as they are reported in literature mentioned above.

\subsection{Developing the design}

To handle these questions a design-experiment was created by considering several designprinciples (emphasised in italics). In order to develop a learning arrangement meeting the research questions, the reduction of copper oxide by hydrogen as an experimental task was chosen. It was expected that learners explicitly verbalize their understanding or at least their thinking-pathways of the chemical formulae and stoichiometric relations corresponding with this task. Students shall deduce details about a chemical reaction and the resulting compound by conducting a chemical experiment.

Therefore, a small amount of the compound is to be weighed into a glass tube and heated in an atmosphere of hydrogen. A reaction starts, observable by a reddish glow, which leads to a red-brown powder that can be identified as copper. The mass of copper is then determined and compared to the previous mass. The difference indicates how much oxygen has left the compound and the stoichiometric relation is quantifiable.

Two approaches should be compared: one pair of students started with the experiment generating the chemical formulae from the gained data. Another group had to predict the experiment's outcome before they conducted it and verify the forecast afterwards. Our hypothesis for this setting was that having the formula in mind while working on the experiment helps to focus on the core-content of the learning arrangement. To be able to 
compare both lines of action, each pair of students uses both proceedings: starting with black copper oxide and in a second setting working with red copper oxide.

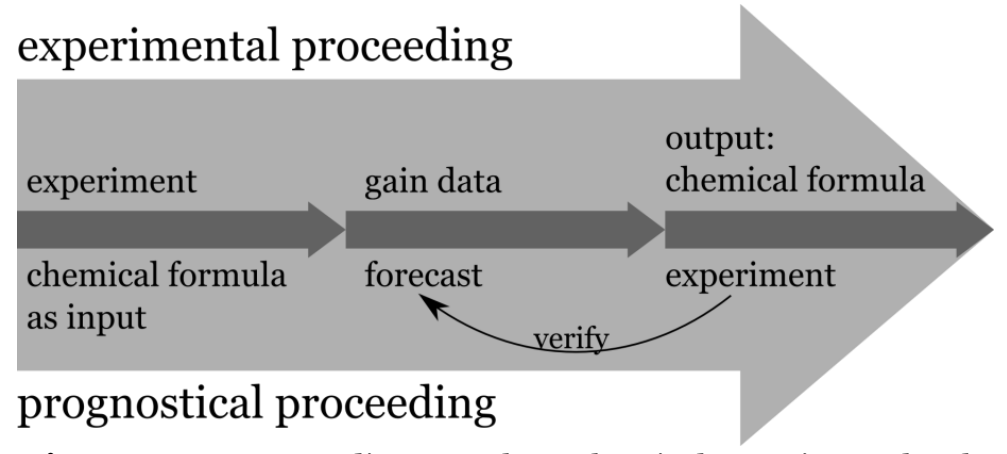

Figure 1: Two proceedings to solve a chemical-experimental task.

By working with chemicals and chemical equipment the students are asked to notice difficulties connected to the experiment. For example the challenge to weigh a powder as exactly as possible, or to observe a very short phenomenon. The design-experiment shall allow students to notice these difficulties and reflect upon them in the phase of analysis. This is necessary for interpreting the gained data and for coming to reasonable conclusions.

The design experiment demands several interactions amongst the learners and between learners and interviewer, respectively. They have to apply their knowledge gained at school or in everyday life, bring in their ideas to solve the tasks and agree on a solution - even if the common solution appears to be a dead end. Students shall discuss and reflect upon their own and other students' knowledge and ideas in the design-experiment.

Finally, the students have to deal with a macroscopic compound, but the explanation they are asked to deduce forces them to argue on a sub-microscopic level. Students shall knowingly perform a shift from the macro level to a sub-micro level.

\subsection{Conducting and analysing design experiments}

As a third step we conducted the learning arrangements with accompanying interviews, following the idea of 'teaching experiments' (Komorek \& Duit, 2004). Pairs of students were confronted with the chemical-experimental task and were asked to solve this task during the interview. The setting was videotaped, so every action and comment made by the students or the interviewer would be available for later analysis. We conducted nine interviews at the university with pairs of students (aged between 14 and 16, eight female, ten male) that lasted about an hour. The interviews were completely transcribed afterwards.

Detailed learning pathways. We decided to focus our analysis on the process the students pass through instead of isolated conceptions. Following the idea of detailed learning pathways, an expert's pathway was created. This pathway maps out the proceeding of an ideal pair of students working in this learning arrangement. It follows common textbook-strategies and brings in all the knowledge students should have learned in their previous schoolcareers. The learning arrangement is divided into several logical sections (preparing the experiment, analysing the observations and data, ...) that have to be passed. For every single 
section the required previous knowledge and all active actions are mapped out. Hereby, different occurrences are listed and chronologically sorted. These events are not only inputs made by the interviewer or the worksheets but also special actions of communication between the two students as well as between students and the interviewer.

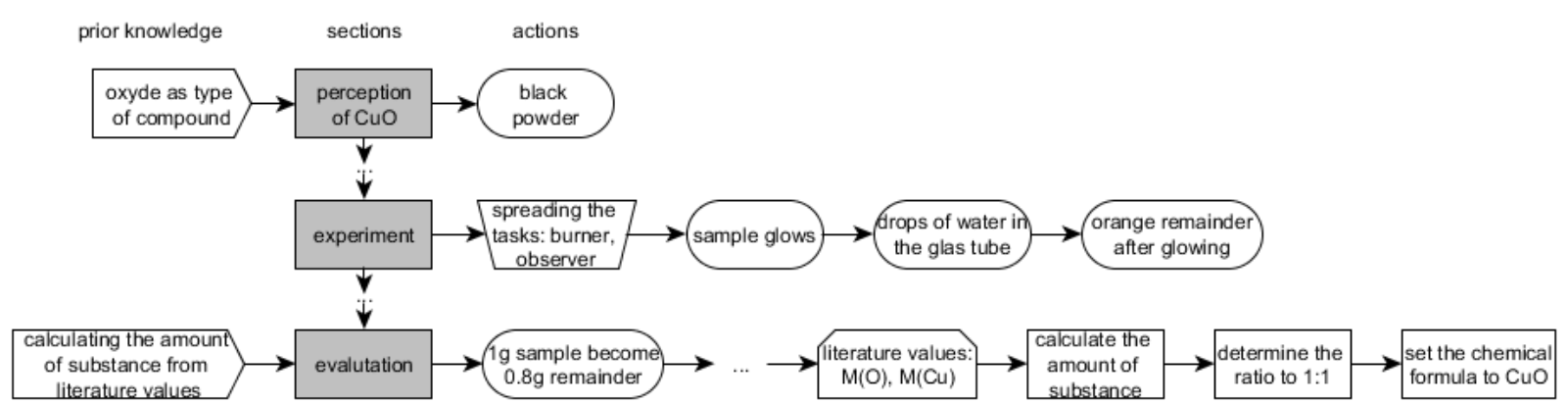

Figure 2: Shortened detail from the expert's pathway

This expert's pathway is meant to be a guideline for the analysis. For every interview an individual learner's pathway is created and compared to the expert's. Variations between the pathways are expected and can indicate problems in the learning arrangement, missing previous knowledge, alternative (maybe incorrect) ways of thinking or individual strategies of solving tasks. By creating these individual detailed learning pathways it is possible to visualize the cognitive actions of a pair of students.

Results of the learning pathway analysis. The variations between the expert's pathway and the individual learners' pathways can be summed up in three categories:

Primarily, many manual problems occur when working on the chemical experiment. Weighing in a small amount of the compound seems to be a big challenge for the learners; even working with a scale is not as common as expected. Most parts of the experimental setup have been prepared before the interview, but letting the students complete the construction did not lead to the expected reflection about difficulties and mistakes. Instead, it distracted from important observations and interpretations. For the following design experiments we decided to reduce the manual work and show videotaped chemical experiments in order to focus the students' attention on the observations and the analysis.

Another category deals with language problems. We found that students are often unable to verbalize their observations adequately. For example, they do not apply chemical terminology suitably, but use the term "burning" to describe the glowing reduction of copper oxide for example or confuse terms like "ions" and "electrons". Additionally, it came to our attention that students seem to be incapable to verbalize more than a few words in a row. Although this was not a focus of our analysis, it created additional problems in interpreting the students' pathways.

As a third category we collected students' efficient individual strategies that do not refer to common textbook approaches and show only few connections to common strategies learned at school respectively. Those ideas of solving a task are mostly unconventional and use different competencies than the common strategies. We suggest that they could be used 
to support weaker or slower learners by activating other cognitive requirements. The example below shall clarify this thesis:

Individual strategies. In four of our nine interviews hints of this strategy can be found. The question as to how much copper can be gained out of one gram $\mathrm{CuO}$ is answered by the expert's pathway by calculating the molar mass and using the compound's amount of substance. The individual strategy we observed deals with the molar masses' ratio $(\mathrm{M}(\mathrm{Cu}) \approx 64 \mathrm{~g} / \mathrm{mol}, \mathrm{M}(\mathrm{O}) \approx 16 \mathrm{~g} / \mathrm{mol})$ that can be shortened to $4: 1$. Thereby, one gram of the compound can be split into five parts, whereof four parts are ascribed to copper and one to oxygen. Consequently, students come to the correct conclusion (about $0.8 \mathrm{~g}$ of copper) with fewer steps of calculation leading to a minor cognitive load. In addition, this strategy operates in a more mathematical way: it uses only the molar masses' figures without referring to their meaning. This simplification could be used as an initial aid for learners that are not familiar with the mole and the corresponding concept. This approach is only applicable to a few compounds ( $\mathrm{CuO}, \mathrm{CuS}, \mathrm{KBr}, \ldots)$, but is expandable if the step of shortening the ratio is left out. Hence, it can be the initiation to the chemical concept and the common strategies.

\subsection{Developing local theories}

The aim of developing local theories about the processes of teaching and learning following the Dortmund Model of didactical design research (Prediger et al., 2012) is reflecting the results and obstacles which occurred and is relating them to the intended goals.

The learning arrangement enables us to investigate the process of how students can construct an understanding of chemical formulae and stimulates the students to reveal their own ideas in the process of investigating the stoichiometric ratio. Furthermore, we can discern students' individual ideas in order to generate initial inputs for slower learners. By using detailed learning pathways, a process-orientated analysis of students' proceedings can take place. Although, we have no authoritative evidence to compare the experimental proceeding to the prognostic proceeding, we expect to gain more information about the students' processes of construction through another type of analysis, described in the outlook.

\section{Outlook}

We do not identify stronger differences regarding the two proceedings (either to start with the experiment of copper reduction or with the forecast) shown in Figure 1 so far. To gain more meaningful results regarding students' pathways we decided to reanalyse the interviews more deeply. Using QDA software (MAXQDA10), we determined relevant phases of the interview, focusing on the parts with a high rate of explanation and interpretation, such as analysing and forecasting the chemical experiment, respectively, or verifying the forecast afterwards.

For these parts of communication we apply a qualitative content analysis (Mayring, 2010) and identify specialties of communication. By a deeper analysis of communication between 
THE COMPLEXITY OF LEARNING AND UNDERSTANDING IN CHEMICAL EDUCATION

the students, for example by an altered use of interpretations and explanations instead of contextless speculations, we expect to identify the prognostic proceeding as the more efficient way.

Moreover, the individual solving strategies of the students shall be investigated in detail with respect to their suitability for teaching and learning processes in classrooms. 


\section{References}

Aufschnaiter, C. von, \& Rogge, C. (2010). Misconceptions or Missing Conceptions? Eurasia Journal of Mathematics, Science \& Technology Education, 6(1), 3-18.

Bernholt, S., Fischer, I., Heuer, S., Taskin, V., Martens, J., \& Parchmann, I. (2012). Die chemische Formelsprache: (un-)vermeidbare Hürden auf dem Weg zu einer Verständnisentwicklung? [Language of chemical formulae]. Chemie Konkret, 19(4), 171-178.

Claesgens, J. \& Stacy, A. (2003). What are Students' initial ideas about amount of Substance?

Fach, M. (2007). Stöchiometrisches Rechnen im Chemieunterricht: Entwicklung, konzeptionelle Einbettung und Optimierung von Lernangeboten auf der Basis empirischer Untersuchungen [Stochiometric calculations in chemistry lessons]. Studien zur Kontextorientierung im naturwissenschaftlichen Unterricht: Vol. 3. Tönning [u.a.]: Der Andere Verlag.

Gravemeijer, K., \& Cobb, P. (2006). Design-Research from a learning design perspective. In Akker, J. J. H. van den (Ed.), Educational design research (pp. 17-51). London, New York: Routledge.

Johnstone, A. H. (1997). Chemistry Teaching - Science or Alchemy? Journal of Chemical Education, 3(74), 262-268.

Mayring, P. (2010). Qualitative Inhaltsanalyse: Grundlagen und Techniken [Qualitative Content Analysis] (11th ed.). Weinheim: Beltz.

Petri, J., \& Niedderer, H. (1998). A learning pathway in high-school level quantum atomic physics. International Journal of Science Education, 20(9), 1075-1088. doi:10.1080/0950069980200905

Prediger, S., Link, M., Hinz, R., Hußmann, S., Thiele, J., \& Ralle, B. (2012). Lehr-Lernprozesse initiieren und erforschen: Fachdidaktische Entwicklungsforschung im Dortmunder Modell. Der mathematische und naturwisschenschaftliche Unterricht, 65(8).

Prediger, S., \& Zwetzschler, L. (2013). Topic-specific design research with a focus on learning processes: The case of understanding algebraic equivalence in grade 8. In T. Plomp \& N. Nieveen (Eds.), Educational design research. Part B: Illustrative cases . Enschede: SLO. Retrieved from http://international.slo.nl/bestanden/Ch20.pdf/

Rossa, E. (1998). Das Mol im Bild [The Mole in a Picture]. Chemie in der Schule, (45), 8-13.

Schmidt, H.-J. (1990). Stolpersteine im Chemieunterricht: Empirische Untersuchungen über Schülerfehler beim stöchiometrischen Rechnen (1st ed.). Frankfurt am Main: Diesterweg.

Scott, P. H. (1992). Pathways in Learning Science: A Case Study of the Development of One Student's Ideas Relating to the Structure of Matter. In R. Duit (Ed.), Research in physics learning. Theoretical issues and empirical studies ; proceedings of an international workshop held at the University of Bremen, March 4 - 8, 1991 (pp. 203-224). Kiel: IPN.

Stübs, R., \& Wegner, G. (1990). Schülertätigkeiten im Bereich der chemischen Zeichensprache in Klasse 7: Ergebnisse, Erfahrungen und Probleme. Chemie in der Schule, 37(20), 463-469.

Taskin, V., \& Bernholt, S. (2014). Students' Understanding of Chemical Formulae: A review of empirical research. International Journal of Science Education, 36(1), 157-185.

van Merriënboer, J., \& Sweller, J. (2005). Cognitive Load Theory and Complex Learning: Recent Developments and Future Directions. Educational Psychology Review, 17(2), 147-177. doi:10.1007/s10648-005-3951-0

Wohlmuth, M. (2005). Die Nanoworld [The Nanoworld]. Praxis der Naturwissenschaften - Chemie, 54(1), 40-43. 